\title{
Changing Students' Perceptions of Matter through the Educational Model of Microcosm
}

\author{
Ourania Gikopoulou \\ Postdoctoral Researcher, National and Kapodistrian University of Athens, Department of Primary Education, \\ Navarinou 13a, GR 106 80, Athens, Greece
}

\begin{abstract}
In this paper we investigate whether a teaching intervention based on the model of the microcosm can help students of elementary school recategorize substances based on their molecular structure instead of based on their physical state and whether this recategorization is related to the change of students' perceptions of matter. The sample consisted of 36 students of $5^{\text {th }}$ grade divided into two groups (control-experimental). They were administered a categorization task and a conception of matter task. The results confirm our hypothesis for the recategorization of substances after the intervention, which affected positively students' concepts about matter, supporting our view that the microscopic approach helps students acquire a better understanding of the macroscopic concepts.
\end{abstract}

Keywords: recategorization; matter; model of microcosm; elementary school

\section{Introduction and Literature Survey}

In this research we investigate if there are changes in the categorization of the concept of matter by elementary school students and whether this recategorization relates to the understanding of scientific concepts.

We support that the difficulties of the students to understand the scientific explanations for physical phenomena are due to the fact that, based on their everyday observations, they form initial interpretations of the phenomena (a naïve theory of matter) before they are exposed to systematic teaching (Vosniadou \& Mason, 2012).

Due to this naive theory, which is substantially different from the scientific, students categorize substances based on their macroscopic properties (physical state) instead of their microscopic structures, and apply to them the properties of the corresponding category ( e.g. solids are hard, liquid spill, gases go up in the sky, etc.). These properties act as constraints to the understanding of the scientific explanations. Therefore the understanding the scientific concepts demands a recategorization of the substances.

More analytically, numerous studies have shown that children face considerable difficulties in understanding the scientific explanations for physical phenomena. Smith, Carey and Wiser (1985) found that students in the age of 10 consider matter continuous. Particulate ideas appear later, but they often are not consistent with the scientific. Nussbaum (1985) showed that even 15 years old students have difficulty understanding the particulate nature of matter and they encounter great difficulty in understanding the concept of vacuum, the perpetual motion of particles and the interaction between them.

Studies of Stavy and Stachel (1985) with children aged 5-12 showed that children can distinguish liquids because the water acts as standard, while they have difficulties for solids, especially for powders or solids that are not hard. Surveys of Nakhleh and Samarapungavan (1999) to pupils aged 7-10 years about the properties of matter in the three physical states showed that even students who had particulate ideas were unable to generalize their ideas in the three states of matter.

According to Driver et al. (1994) students consider "solids" the objects that are hard, do not break easily and generally are tough, therefore pliable or frangible materials are not included in the solids. The same applies for dusts and powders, because of they can be transferred from one container to another "as if they were liquids". For liquids, the reference standard is the water, therefore viscous liquids such as honey pose difficulties to students. Moreover, young students consider that air is not and has no weight.

Summarizing, we could say that students understand the matter as constant, and even when they refer to particles, they apply to them macroscopic features and properties. Moreover students have formed the view that the identity of substances is determined by a few macroscopic properties and by their physical condition, and that is the reason why they face great difficulties in understanding the scientific explanations for physical phenomena.

Accoring to the framework theory that has been proposed by Vosniadou (Vosniadou \& Mason, 2012) and as it is evident from relevant studies (Vosniadou \& Brewer, 1992; Vosniadou, 2006; Vosniadou \& Vamvakousi, 2006; Vosniadou \& Verschaffel , 2004; Vosniadou, Vamvakousi, \& Skopeliti, 2008), students often find it difficult to understand some concepts they are taught because they violated many of the principles of their naive theories, which are well established. In this case learning cannot be achieved by the addition of new information or by filling the gaps, but requires radical conceptual changes and reorganization of concepts.

Carey (1985) supports that conceptual change often requires recategorization of a concept into a different ontological category or create new ontological categories while sometimes requires differentiating or uniting concepts e.g. differentiation of the concepts heat-temperature or weightdensity (Carey, 1985; Carey \& Spelke, 1994; Wiser \& Carey, 1983). 


\section{International Journal of Science and Research (IJSR) \\ ISSN (Online): 2319-7064}

Index Copernicus Value (2015): 78.96 | Impact Factor (2015): 6.391

Chi (2008) also refers to the importance of the change of category for conceptual change and argues that it is difficult to change the erroneous idea when a concept is categorized into a false ontological category, because the properties of this category are applied to the concept. To correct such misunderstandings it is necessary for the student to understand the correct category in which the concept really belongs to. When a concept is included into a new category, it means that the laws and principles applicable to the new category now apply also to this concept, i.e. new characteristics and properties are now attributed to the concept (Medin \& Rips, 2005).

The question that concerns us is how the understanding of the scientific explanations is related to the recategorizations of substances form the categorization based on the physical state to the categorization on the basis of the molecular structure. In particular, we are interested to investigate how elementary school students categorize substances, whether we can facilitate their recategorizations and whether this relates to the process of understanding the scientific explanations about changes of matter.

Therefore, we examine whether a teaching intervention based on the educational model of microcosm (with appropriate simulations) can help elementary school students recategorize substances based on their particle structure instead of their physical state. We also examine whether this recategorization is related to their explanations about the physical changes of matter.

\section{Method / Approach}

This study examines how students categorize objects in relation to their conceptions of matter. We design and implement a teaching intervention based on the model of microcosm. This intervention aims to help students move from their naïve theory of matter which is based on their senses to the abstract concepts that characterize the particulate scientific theory of matter.

The aim of the study was to determine if there is recategorization of the concept of matter after the intervention and to examine the correlation between students' categorizations and their conceptions of matter.

\subsection{Hypotheses}

We hypothesized that after the implementation of our intervention there will be changes in the students' categorizations of objects.

We also hypothesized that there will be a strong correlation between the students' categorizations and their conceptions about matter. We expected that students who will categorize substances based on their physical state will have naive conceptions about matter, while students who will categorize them based on their common molecular structure despite their macroscopic properties will have conceptions of matter closer to the scientific.

According to our theoretical framework, the transition from the categorization of substances based on their physical state to their categorization on the basis of their molecular structure appears to be a prerequisite for the understanding of scientific concept of matter.

To enable students' understanding of the scientific concept of matter seems to be necessary a recategorization of matter into a new ontological category where new properties are applied to it (Medin \& Rips, 2005; Vosniadou, Vamvakoussi, \& Skopeliti, 2008).

To test these hypotheses, we conducted an empirical study with elementary school students. We used a Categorization Task and a Conceptions of Matter Task.

\subsection{Participants}

The sample was 36 students of $5^{\text {th }}$ grade (10-11 years old) of a public elementary school, divided into two groups, control and experimental.

The choice of this grade was based on our previous research, which showed that by the end of elementary school students have formed a naive theory of matter based on the senses, where substances are categorized based on their macroscopic properties. Moreover in this grade begins the teaching of the concepts of matter on the basis of the curriculum and the corresponding textbook.

\subsection{Materials}

The "Categorization Task", used also in our previous studies (Gikopoulou \& Vosniadou, 2006), consisted of 8 cards with the names of 8 objects which the participants were asked to categorize: ice, rain, cloud, water, hail, vapor, fog, snow. These objects could be categorized either based on their physical state (solid, liquid, gas) or based on their common molecular structure $\left(\mathrm{H}_{2} \mathrm{O}\right)$ as shown in Table 1. Four categorization questions were asked and each of them was followed by a justification question ("why did you put these things together?"): 1 . I want you to put together the things that you think should go together, belong to the same group. 2. Is there another way you can put these things together? 3 . Could you put in one group the things that are solid, in another the liquids and in another the gasses? 4. Could all these things be in the same group?

Table 1: Categorizations of objects

\begin{tabular}{|l|c|}
\hline & \multicolumn{2}{|c|}{ Molecular structure $\left(\mathbf{H}_{\mathbf{2}} \mathbf{O}\right)$} \\
\hline Solids & ice snow hail \\
\hline Liquids & $\ldots$ \\
\hline Gasses & vapor cloud fog \\
\hline
\end{tabular}

The "Conceptions of Matter Task" investigating students' conceptions about matter and its properties is an adjusted and enriched version of Smith's (2007) task, used also in previous researches (Gikopoulou \& Vosniadou, 2012a-2012b). It consists of 18 questions about mass, weight, volume, density, measurements, matter and materials. Namely, students are asked whether some objects have weight and mass or not: e.g. a tiny piece of Styrofoam (non felt weight and small volume), a big piece of Styrofoam (small weight and big volume), a tiny piece of clay (small weight and small volume), a big piece of clay (felt weight and big volume), ten sugar grains (little 


\section{International Journal of Science and Research (IJSR) \\ ISSN (Online): 2319-7064}

Index Copernicus Value (2015): 78.96 | Impact Factor (2015): 6.391

weight, enough quantity) and one sugar grain (non felt weight). Students are also asked to calculate the volume and the mass of an object and to distinguish the material bodies from the non material. Finally, they are asked to draw sketches of the interior of a solid, a liquid and a gas and refer to their properties as well as to the conservation of matter.

\subsection{The intervention}

For the design of the intervention we took into consideration the perceptions of students of this age (10-12 years old) about matter as well as the proposed order of the macroscopic concepts required for the introduction of the particulate theory, which is achieved with appropriate simulations of the model of microcosm.

With respect to the microscopic model, its introduction is achieved in a systematic way, without the use of mathematics and with the appropriate simulations, created in the Science and Technology Laboratory of National and Kapodistrian University of Athens (Kalkanis, 2006-2013).

For the creation of the simulations the most common students' alternative conceptions of matter recorded in literature were taken into consideration in order to prevent their enhancement: e.g. particles move constantly and are presented on a black background, so as not to give the impression that there is something between them. Moreover, in order to facilitate students, we attempted to combine the microscopic model with the macroscopic approach and examine concepts from both aspects simultaneously. Therefore we used animations, videos, depiction of both macroscopic and microscopic aspects, successive enlargements of objects depicting their interior, analogies introducing the idea of matter consisting of particles and simulations of solids that are heated and converted to solids and then to gasses.

The intervention at the experimental group lasted for 10 hours and included the basic concepts about matter that students are taught in this grade (matter, volume, mass, weight, density) as well as a more analytical description of the microscopic model with the use of the simulations. In each lesson students wrote down their observations and conclusions after they conducted the experiments in groups of 4 or 5 , following the same methodology implemented in the official science textbooks (Apostolakis et al., 2006). The control group students were taught also for 10 hours the corresponding concepts from the official textbook and a very general introduction on the structure of matter through the figures of the book. The lessons followed the same methodology and students also conducted experiment in groups of 4 or 5 .
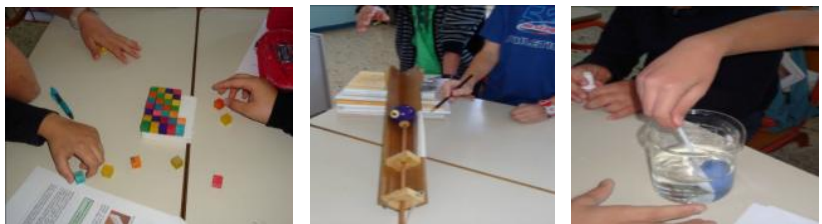

Figures 1a, 1b, 1c: students worked in groups conducting experiments

\subsection{Procedure}

Participants were interviewed individually. The interviews lasted about 30 minutes and took place in the school class, without the presence of others. The questions asked were the same for all participants and with the same order.

Participants recorded their answers and drew their sketches in a worksheet given to them, while the researcher was taking notes.

Initially it was administered to the students of both groups the Categorization Task and then the Conceptions of Mater Task (as pre-tests).

Then, the suggested intervention was implemented for 10 hours at the experimental group, whereas at the control group students were taught also for 10 hours the corresponding concepts from the books.

After the intervention, students of both groups were administered again the same tasks with the same procedure (as post-tests) in order to examine the effectiveness of the intervention.

\section{Results / Discussion}

In order to examine our first hypothesis concerning the effectiveness of our intervention we present initially the students' answers (of both groups) in the two Taks before and after the intervention and compare their performances. Then we examine the correlation between students' categorizations and their conceptions about matter, in order to test our second hypothesis.

\subsection{Scoring of Tasks and students' answers}

At the Categorization Task we focused on the last two questions because we wanted to test whether students who categorize objects according to their physical state (solid, liquid, gas) can categorize them also on the basis of their molecular structure or not.

By the combination of their different responses to these two questions arose three different types of answers based on their categorization criteria, which are shown in figures 2-3.

(1) Similarity: students do not categorize objects into solids, liquids and gases nor place them in one category. This type of answer was scored as 1 .

(2) Physical state: students categorize objects into solids, liquids and gases but do not place them in one category (they often answer that they do not match or that solids, liquids and gases cannot be put together). This type of answer was scored as 2 .

(3) Microscopic: students categorize objects into solids, liquids and gases, and also place them all in one category, justifying their answer saying that they are all water in different physical sate or it is the solid, liquid and gaseous state of water or they are all the same chemical compound $\mathrm{H} 2 \mathrm{O}$, etc. This type of answer was scored as 3 . 
International Journal of Science and Research (IJSR)

ISSN (Online): 2319-7064

Index Copernicus Value (2015): 78.96 | Impact Factor (2015): 6.391

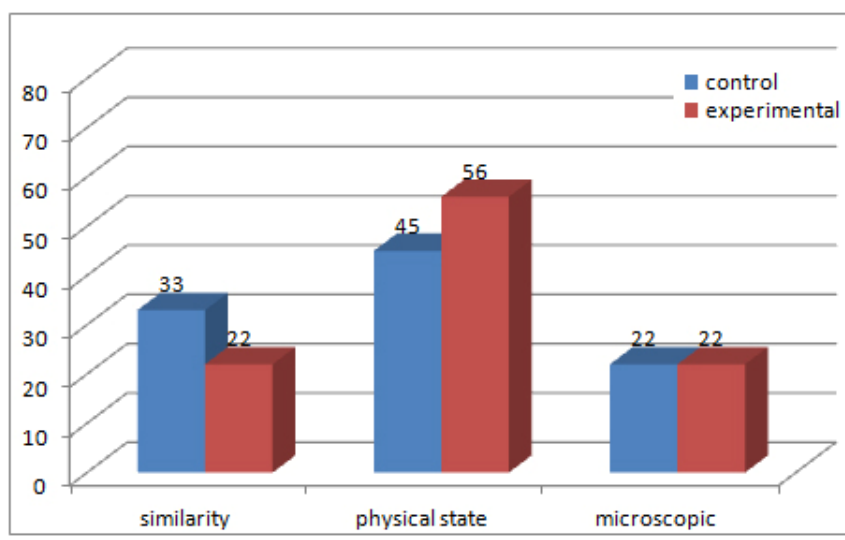

Figure 2: Percent responses in the categorization task (pretest)

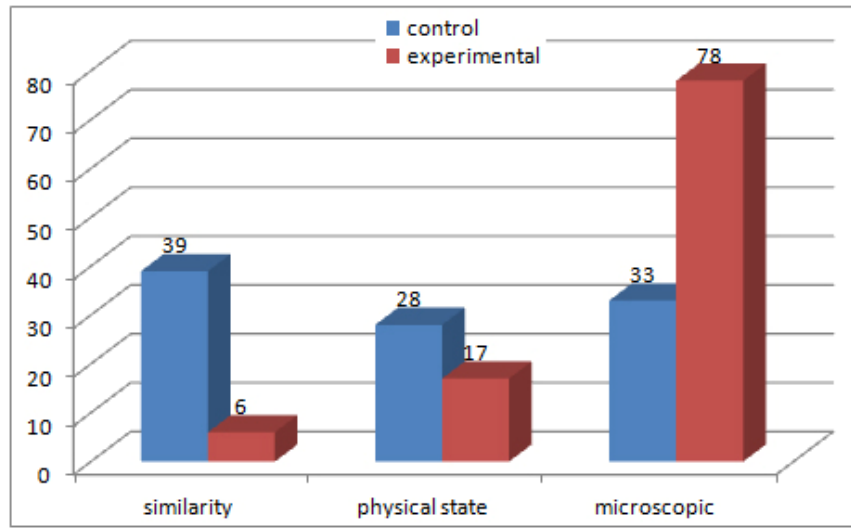

Figure 3: Percent responses in the categorization task (posttest)

At the Conception of Matter Task, the criteria we used to group students' responses were if they understand matter on the basis of their senses or as a basic component that has weight and takes up space; if they believe that matter is maintained or disappears after successive divisions or when is not visible; if they differentiate the concepts of weight and mass; if they you identify the materials based on appearance or on their senses; if they consider matter static and continuous or make reference to particles.

Based on these criteria and their answers to all the questions the students were grouped into five categories, shown in figures 3-4.

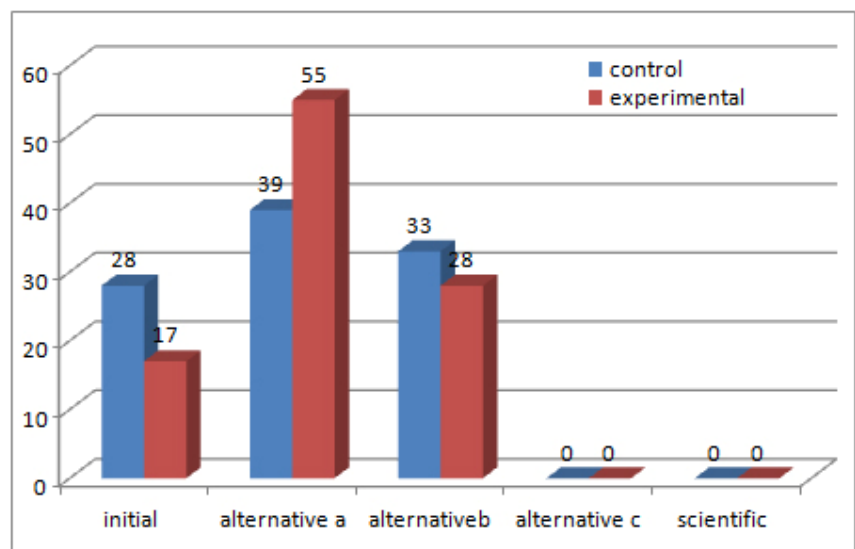

Figure 4: Percent responses in the conceptions of matter task (pre-test)

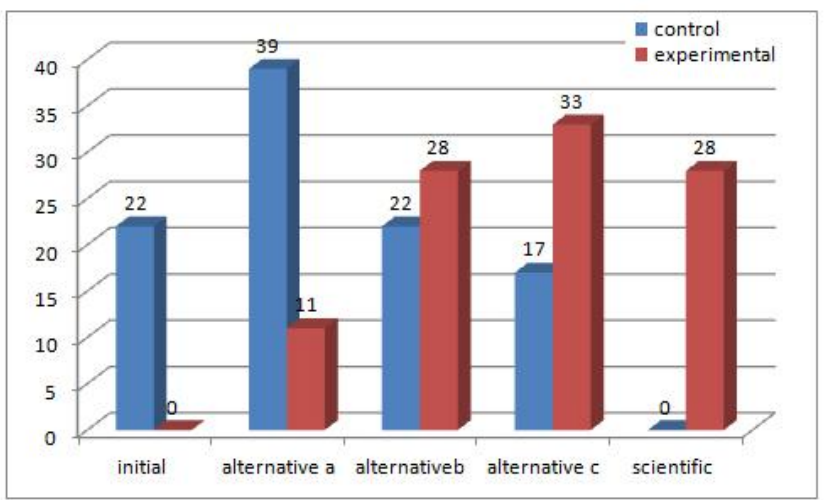

Figure 5: Percent responses in the conceptions of matter task (post-test)

(1) Initial: matter perceived by all senses. The understanding of matter is based on the senses therefore small and invisible bodies have no volume, mass or weight; matter disappears after successive divisions; materials are identified based on their appearance and behavior and there is difficulty in distinguishing matter from non-matter; matter is considered to be static and continuous. This type of answer was scored as 1 .

(2) Alternative a: matter with perceptible weight or volume.

The small piece of clay has mass, volume and weight, but small light objects (such as Styrofoam and one sugar grain) and invisible objects have no volume, mass or weight; matter disappears after successive divisions; matter is a kind of material, which is solid, liquid or gas; matter is considered to be static and continuous. This type of answer was scored as 2 .

(3) Alternative b: matter visible. The understanding of matter is again based on the senses, but students now accept that even small light objects have volume, mass and weight, while the invisible objects are still considered to be without; matter disappears after successive divisions; it may be matter we cannot see, but this piece of matter does not have weight or volume; as for the properties of matter are not applied to all objects; the material / non-material distinction is successful for most solids and liquids, but the gases or small objects (e.g. smoke, rust, chalk dust etc.) still confuse students; matter is static and continuous or students refer to particles but there are misconceptions or incomplete understanding. This type of answer was scored as 3 .

(4) Alternative c: matter also invisible. Matter is a basic component that has weight and occupies space; all objects have volume, mass, weight; matter continues to exist as divided into small pieces and each of them has weight and occupies space, even when they are not visible; the material / non-material distinction is made with some success, but the gases or small objects (smoke, rust, chalk dust) still confuse students; matter consists of particles but there are still misconceptions or incomplete understanding. This type of answer was scored as 4.

(5) Scientific: matter as basic component. Matter is a basic component that has weight and occupies space; matter continues to exist as divided into small pieces and each of them has weight and occupies space, even when they are not visible to our senses; with regard to the properties of matter, the materials are basic components that retain their identity and are characterized by objective and measurable properties instead of their appearance or perceptible properties; there is 


\section{International Journal of Science and Research (IJSR) \\ ISSN (Online): 2319-7064}

Index Copernicus Value (2015): 78.96 | Impact Factor (2015): 6.391

successful material / non-material distinction; matter consists of particles not visible to us, which are constantly moving. This type of answer was scored as 5 .

\subsection{Comparison of groups' performance}

In order to test the effectiveness of the proposed intervention we compared the students' performance in the pre-tests and the post-tests. The total scores of students' performance in each task were subjected in an one way ANOVA which, as expected showed main effects for group in favor of the experimental group only for the post-tests as shown in tables 2 and 3.

Table 2: Comparison of students' performance in the pretests (2 tasks)

\begin{tabular}{|c|c|c|c|}
\hline Pre-test & One-Way Anova & $\begin{array}{c}\text { control } \\
\text { mean }\end{array}$ & $\begin{array}{c}\text { experim. } \\
\text { mean }\end{array}$ \\
\hline Categorizations & $\mathrm{F}(1,34)=0.213, \mathrm{~ns}$ & $1.89 / 3$ & $2.00 / 3$ \\
\hline Conceptions of Matter & $\mathrm{F}(1,34)=0.050, \mathrm{~ns}$ & $2.06 / 5$ & $2.11 / 5$ \\
\hline
\end{tabular}

Table 3: Comparison of students' performance in the posttests ( 2 tasks)

\begin{tabular}{|c|c|c|c|}
\hline Post-test & One-Way Anova & $\begin{array}{c}\text { control } \\
\text { mean }\end{array}$ & $\begin{array}{c}\text { experim. } \\
\text { mean }\end{array}$ \\
\hline Categorizations & $\begin{array}{c}\mathrm{F}(1,34)=0.976, \\
\mathrm{p}=0.003\end{array}$ & $1.94 / 3$ & $2.72 / 3$ \\
\hline Conceptions of Matter & $\begin{array}{c}\mathrm{F}(1,34)=18.184, \\
\mathrm{p}<0.001\end{array}$ & $2.33 / 5$ & $3.78 / 5$ \\
\hline
\end{tabular}

It seems that the students of both groups (control, experimental) had similar performance to both tasks before the intervention, however there are observed statistically significant differences in their performance after the intervention with the experimental group attaining higher performance in comparison to the control group in both tasks.

We also compared, the performance of each groups' students separately before and after the intervention. The Paired Samples t-test showed statistically significant differences only for the experimental group, as shown in tables 4 and 5 .

Table 4: Comparison of control groups' performance in the tasks before and after the intervention

\begin{tabular}{|c|c|c|c|}
\hline Control group & $\begin{array}{c}\text { Paired samples } \\
\mathrm{t} \text {-test }\end{array}$ & $\begin{array}{c}\text { Pre } \\
\text { mean }\end{array}$ & $\begin{array}{c}\text { Post } \\
\text { mean }\end{array}$ \\
\hline Categorizations & $\mathrm{t}=-0.325, \mathrm{~ns}$ & $1.89 / 3$ & $1.94 / 3$ \\
\hline Conceptions of Matter & $\mathrm{t}=-2.051, \mathrm{~ns}$ & $2.06 / 5$ & $2.33 / 5$ \\
\hline
\end{tabular}

Table 5: Comparison of experimental groups' performance in the tasks before and after the intervention

\begin{tabular}{|c|c|c|c|}
\hline Experimental group & $\begin{array}{c}\text { Paired samples } \\
\text { t-test }\end{array}$ & $\begin{array}{c}\text { Pre } \\
\text { mean }\end{array}$ & $\begin{array}{c}\text { Post } \\
\text { mean }\end{array}$ \\
\hline Categorizations & $\mathrm{t}=-4.579, \mathrm{p}<0.001$ & $2.00 / 3$ & $2.72 / 3$ \\
\hline Conceptions of Matter & $\mathrm{t}=-8.416, \mathrm{p}<0.001$ & $2.11 / 5$ & $3.78 / 5$ \\
\hline
\end{tabular}

There is no statistically significant differences in the performance of students of the control group in the post-tests in relation to the pre-tests (although it is observed an improvement in their performance), whereas in the experimental group there is statistically significant differences in favor of the post-tests in both tasks.

In other words, the control group students showed no significant improvement in their performance after the intervention, in contrast to the students of the experimental group, whose performance improved significantly in both tasks, proving the success of the proposed intervention. These results seem to confirm our first hypothesis since we found that the proposed intervention facilitated students' recategorizations of substances from categorizations based on their macroscopic properties to categorizations based on their microscopic structure. The intervention had also positive effect on students' conceptions of matter and helped the move from their initial conceptions to conceptions more close to the scientific ones.

\subsection{Correlations}

In order to test our second hypothesis we examined the correlations between the students' categorizations and their conceptions of matter. According to our second hypothesis, we expected that students who categorize substances on the basis of their physical state will also have initial conceptions of matter in relation to the students who categorize substances based on their molecular structure.

The correlation indicator Spearman rho (categorizations $x$ conceptions of matter) showed statistical significant correlation between students' categorizations and their conceptions of matter, both at pre-tests and at post-tests. Pre-tests: rs $=0.670$, $\mathrm{p}<0.001$ and Post-tests: $\mathrm{rs}=0.861, \mathrm{p}<0.001$.

Table 6: Correlation between students' categorizations and their conceptions of matter - Post-tests

\begin{tabular}{|c|c|c|c|c|c|}
\hline \multirow{2}{*}{$\begin{array}{c}\text { Catego- } \\
\text { rizations }\end{array}$} & initial & $\begin{array}{c}\text { alternative } \\
\mathrm{a}\end{array}$ & $\begin{array}{c}\text { alternative } \\
\mathrm{b}\end{array}$ & $\begin{array}{c}\text { alternative } \\
\mathrm{c}\end{array}$ & scientific \\
\cline { 2 - 6 } & $\begin{array}{c}4 \\
\text { Similarity } \\
(100 \%)\end{array}$ & $\begin{array}{c}4 \\
(44 \%)\end{array}$ & - & - & - \\
\hline $\begin{array}{c}\text { Physical } \\
\text { state }\end{array}$ & - & $\begin{array}{c}5 \\
(56 \%)\end{array}$ & $\begin{array}{c}3 \\
(33 \%)\end{array}$ & - & - \\
\hline Microscopic & - & - & $\begin{array}{c}6 \\
(67 \%)\end{array}$ & $\begin{array}{c}9 \\
(100 \%)\end{array}$ & $\begin{array}{c}5 \\
(100 \%)\end{array}$ \\
\hline
\end{tabular}

As shown in Table 6, all students who had scientific conception of matter can also categorize objects on the basis of their molecular structure apart from their physical condition. The same is true for the students who had an alternative $\mathrm{c}$ conception of matter which is close to the scientific one. On the other hand, all students with initial conception of matter did not categorize objects based on their physical state nor their molecular structure but based on their similarity. At the interim alternative $a$ and $b$ conceptions of matter the rates are divided. Similar results were obtained also at the pre-tests.

\subsection{Regression}

To examine more thoroughly the relationship between the students' categorizations and their conceptions of matter we conducted a regression analysis. Regression analysis (with the conceptions of matter as the dependent variable and the categorizations as a predictive factor) was statistically significant $F(1,34)=83.821, p<0.001, R 2=0,703$. Students' categorizations seem to be an important predictive factor for their conceptions of matter (Beta $=0,843, \mathrm{p}<0,001)$. It

\section{Volume 6 Issue 1, January 2017




\section{International Journal of Science and Research (IJSR) \\ ISSN (Online): 2319-7064}

Index Copernicus Value (2015): 78.96 | Impact Factor (2015): 6.391

seems that if we know students' categorizations we can predict $70 \%$ of their conceptions of matter.

Consequently it seems that the change of categorization of matter from based on its physical state to the categorization based on its molecular structure precedes the complete understanding of the scientific conception of matter and it seems to be a necessary but not sufficient prerequisite for this understanding.

\section{Conclusions}

The results of the study confirmed our hypothesis for the recategorization of substances after the intervention, which has affected positively also students' conceptions of matter, as we found statistically significant differences between the two groups, with the experimental group attaining higher performance. We also found a high degree of correlation between students' categorizations and their perceptions matter both before and after the intervention, confirming our second hypothesis.

The students of the experimental group achieved statistically significant higher performance in both tasks in comparison to the students of the control group. Specifically, most students in the experimental group:

- Moved from categorizations based on similarity or physical state to categorizations based on the microscopic structure $(78 \%)$. In the control group students this percentage was significantly lower (33\%).

- Moved from their initial conceptions matter to alternative closer to the scientific (33\%), while $28 \%$ of them reached the scientific concept.

- Appear to accept the concept of non visible particles as basic components of matter and consider the weight and volume as the properties of matter, even in its nonvisible form.

Moreover, the combination of the two approaches, macroscopic and microscopic, proved successful and effective, as students responded successfully and were attempting themselves to find the microscopic explanation for the macroscopic phenomena they studied.

Our results support the view that the recategorization of substances from based on their macroscopic properties to based on their microscopic structure is a prerequisite for understanding the scientific concept of matter. Our findings also support the education model of microcosm (with appropriate simulations) helps students acquire a better understanding of the scientific concept of matter.

Our results are consistent with other researchers (Wiser and Smith 2008, 2012a, 2012b) who argue that the microscopic approach of matter at this age helps students consolidate their understanding of matter and approach other macroscopic concepts which are not easily explained without the particle theory (e.g. change of state).

These results also confirm previous arguments about theory change to conceptual knowledge of children (Carey, 1985. Chi, 1992; Vosniadou, 1999) and seem to confirm experimentally that the process of conceptual change requires ontological changes (Carey, 1991; Inagaki \& Hatano, 2002). Therefore they enhance our theoretical framework for the relationship of conceptual change and the process of categorizations. We believe that children from an early age form naive theories of physics (Vosniadou \& Mason, 2012) and on that basis they organize concepts automatically into categories, applying to them the properties of these categories (Carey, 1985; Murphy \& Medin, 1985). Most of the students misunderstandings are due to such incorrect categorizations (Chi, 2008). Subsequently, when the students' explanatory framework is enriched and restructured, automatically are influenced their categorizations of concepts. When a concept is recategorized new features and properties are attributed to it, because the laws and principles applicable to the new category are now applied to this concept (Medin \& Rips, 2005).

\section{Future Scope}

Our research supports the view that the difficulties of students to understand the scientific concept of matter result from their tendency to categorize objects according to their macroscopic properties (instead of the molecular structure) and that the recategorization of the concept of matter in a new ontological category seems to be necessary for a full understanding of the scientific concepts.

These difficulties of students are often enhanced because the issue of conceptual change is ignored during teaching. Many teachers believe that the new information can be easily incorporated into the existing knowledge of students, and do not realize that sometimes the existing knowledge can stand in the way when new information is not compatible with the existing (Vosniadou, Vamvakousi, Skopeliti, 2008).

Therefore it is important to explore the ways of improving the learning process and facilitating conceptual change. Traditional curricula often underestimate the ability of school students to construct theories and to develop the bases needed for the reconceptualization (Wiser et al. 2012a, 2012b). Essential for this reconceptualization is the transition from the based on senses explanations to explanations based on the more abstract scientific. The unifying model of microcosm can be a very useful tool for promoting conceptual change of the concept of matter.

\section{Acknowledgements}

The research was supported financially by the Foundation for Education and European Culture (Founders: Nicos \& Lydia Tricha, Lysikratous 12, Athens 10558, Greece).

\section{References}

[1] Apostolakis E., Panagopoulou E., Savas S., Tsagliotis N., Makri V., Pantazis G., Petrea K., Sotiriou S., Tolias V., Tsagkogeorga A., Kalkanis G. (2006). Official Science Textbooks for the 5th and 6th grade of Primary Education, Science - I Investigate and Discover, Greek Ministry of Education - Pedagogical Institute, Athens, 2006.

\section{Volume 6 Issue 1, January 2017 \\ www.ijsr.net}

Licensed Under Creative Commons Attribution CC BY 


\section{International Journal of Science and Research (IJSR) \\ ISSN (Online): 2319-7064}

Index Copernicus Value (2015): 78.96 | Impact Factor (2015): 6.391

[2] Carey, S. (1985). Conceptual Change in Childhood. Cambridge, MA: MIT Press.

[3] Carey, S. (1991). Knowledge Acquisition: Enrichment or Conceptual Change? In S. Carey \& R. Gelman (Eds.), The Epigenesis of Mind: Essays on Biology and Cognition (pp. 257-292). Hillsdale, NJ: Lawrence Erlbaum Associates.

[4] Carey, S., \& Spelke, E.S. (1994). Domain specific knowledge and conceptual change. In L. Hirschfeld \& S. Gelman (Eds.), Domain-specificity in cognition and culture (pp. 169-200). New York, NY: Cambridge University Press.

[5] Chi, M.T.H. (1992). Conceptual change within and across ontological categories: Examples from learning and discovery in science. In R. Giere (Ed.), Cognitive Models of Science: Minnesota studies in the philosophy of science. Mineapolis, MN: University of Minnesota Press.

[6] Chi, M.T.H. (2008). Three types of conceptual change: Belief revision, mental model transformation, and categorical shift. In S. Vosniadou (Ed.), International handbook of research on conceptual change (pp. 61-82). New York, NY: Routledge.

[7] Driver, E. Guesne, \& A. Tiberghien (1985). Children's Ideas in Science. Open University Press.

[8] Gikopoulou, R., \& Vosniadou, S., (2006). Categorizations of Substances in Relation to Explanations of Changes in the State of Matter. Paper presented at the 5th European Symposium on Conceptual Change on Bridging the Gap between Mental Models and Situated Cognition? Theoretical and Methodological Considerations. Stockholm, Sweden.

[9] Gikopoulou R. \& Vosniadou S. (2012a). Designing Learning Environments for Teaching Theory of Matter in Primary school. Paper presented at the 8th International Conference on Conceptual Change, University of Trier

[10] Gikopoulou R. \& Vosniadou, S. (2012b). Changes in the Categorization of the concept of "Matter". (Greek) Journal Psychology, 2012, 19 (1), 1-21

[11] Inagaki, K., \& Hatano, G. (2002). Young children's naïve thinking about the biological world. Philadelphia, PA: Psychology Press.

[12] Kalkanis G., (2006). Dynamic Simulations of the microcosm, Science Laboratory, Department of Primary Education, National and Kapodistrian University of Athens, http://micro-kosmos.uoa.gr, accessed 12.12.16.

[13] Kalkanis, G., (2013). From the Scientific to the Educational: Using Monte Carlo Simulations of the microKosmos for Science Education by Inquiry. In Georgios Tsaparlis and Hannah Sevian (Eds.), Concepts of Matter in Science Education, editors. Springer.

[14] Medin, D.L., \& Rips, L.J. (2005). Concepts and categories: memory, meaning and metaphysics. In K.J. Holyoak \& R.G. Morrison (Eds.), Cambridge Handbook of Thinking and Reasoning (pp. 37-72). Cambridge: Cambridge University Press.

[15] Murphy, G.L., \& Medin, D.L. (1985). The Role of Theories in Conceptual Coherence. Psychological Review, 92(3), 289-316.

[16] Nakhleh M., Samarapungavan A., Saglam Y., (2005). Middle School Students' Beliefs about Matter. Journal of Research in Science Teaching, vol. 42, no. 5, 581612

[17] Nussbaum J., (1985). The particulate nature of matter in the gaseous phase. In R. Driver, E. Guesne, \& A. Tiberghien (Eds.), Children's ideas in science (pp. 124144). Milton Keynes, UK: Open University Press.

[18] Smith, C.L., (2007). Bootstraping Processes in the Development of Students' Commonsense Matter Theories: Using Analogical Mappings, Thought Experiments and Learning to Measure to Promote Conceptual Restrucruring. Cognition and Instruction, volume 25 , issue 4 , p. 337-398

[19] Smith C., Carey S., Wiser M., (1985). On differentiation: A case study of the development of the concepts of size, weight and density. Cognition, 21, $177-237$

[20] Stavy R., Stachel D., (1985). Children's ideas about "solid" and "liquid". European Journal of Education, 7, 407-421

[21] Vosniadou, S. (1999). Conceptual Change Research: State of the Art and Future Directions. In W. Schnotz, S. Vosniadou \& M. Carretero (Eds.), New Perspectives on Conceptual Change (pp. 3-13). Oxford: Elsevier Science.

[22] Vosniadou, S. (2006). The Conceptual Change Approach in the Learning and Teaching of Mathematics: An introduction. In Novotná, J., Moraová, H., Krátká, M. \& Stehlíková, N. (Eds.), Proceedings, 30th Conference of the International Group for the Psychology of Mathematics Education, Vol. 1, pp. 155 159. Prague: PME.

[23] Vosniadou, S. \& Brewer, W.F. (1992). Mental models of the earth: a study of conceptual change in childhood. Cognitive Psychology, 24, 535-585

[24] Vosniadou, S., \& Mason, L. (2012). Conceptual Change induced by Instruction: A Complex Interplay of Multiple Factors. In K.R. Harris, S. Graham \& T. Urdan (Eds.), APA Educational Handbook. Vol. 2: Individual Differences and Cultural and Contextual Factors. American Psychological Association.

[25] Vosniadou, S., \& Vamvakoussi, X. (2006). Examining mathematics learning from a conceptual change point of view: Implications for the design of learning environments. In L. Verschaffel, F. Dochy, M. Boekaerts and S.Vosniadou (Eds.), Instructional psychology: Past, present and future trends - Fifteen essays in honour of Erik De Corte (pp. 55-72). Oxford: Elsevier.

[26] Vosniadou, S., Vamvakousi, X., \& Skopeliti, E. (2008). The Framework Theory Approach to the Problem of Conceptual Change. In S. Vosniadou (Ed.), International Handbook of Research on Conceptual Change (pp. 3-34). New York, NY: Routledge.

[27] Vosniadou, S., \& Verschaffel, L. (2004) . Extending the conceptual change approach to mathematics learning and teaching . Learning and Instruction, 14, $445-451$, doi:10.1016/j.learninstruc.2004.06.014

[28] Wiser, M., \& Carey, S. (1983). When heat and temperature were one. In D. Gentner \& A. Stevens (Eds.), Mental models (pp. 267-297). Hillsdale, NJ: Erlbaum.

[29] Wiser M. \& Smith C., (2008), Teaching about matter in grades K-8: When should the atomic-molecular theory 


\section{International Journal of Science and Research (IJSR) \\ ISSN (Online): 2319-7064}

Index Copernicus Value (2015): 78.96 | Impact Factor (2015): 6.391

be introduced? In Stella Vosniadou (Ed.) International Handbook of Research on Conceptual Change

[30] Wiser \& Smith (2012a), Learning and Teaching about Matter in Elementary Grades: What Conceptual Changes Are Needed? In Stella Vosniadou (Ed.) International Handbook of Research on Conceptual Change, 2nd edition

[31] Wiser M., Smith C., (2012b), Learning and Teaching about Matter in the Middle School Years: How Can the Atomic-Molecular Theory be Meaningfully Introduced? In Stella Vosniadou (Ed.) International Handbook of Research on Conceptual Change, 2nd edition

\section{Author Profile}

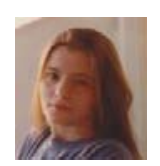

Ourania Gikopoulou is Postdoctoral Researcher of the Pedagogical Department of Primary Education of the National and Kapodistrian University of Athens (NKUA), Teacher of primary education. Studies: PhD on Cognitive Science and Science Education, MSc in Basic and Applied Cognitive Science, MEdu in Science Education, Degree of Pedagogical Department of Primary Education. Educational Activities: teaching at a public elementary school, teaching and supervision of undergraduate and graduate students in Science Laboratory of the Department of Primary Education of NKUA, laboratory assistant and co-teaching of the course "Applications of digital technologies in education" to students of NKUA Postgraduate Program. Research Activities: cognitive science, science education, experimentation in science, the educational model of microcosm, participation in 18 educational research projects. Publications: 3 books, 10 titles of educational software, 19 papers in proceedings of scientific conferences and journals with referees, 42 presentations in scientific conferences with referees. 